\title{
Gingival immunologic defense index: a new indicator for evaluating dental plaque infection risk in allergic children
}

\author{
Seno Pradopo ${ }^{1}$ and Haryono Utomo ${ }^{2}$ \\ ${ }^{1}$ Department of Pediatric Dentistry, Faculty of Dentistry, Airlangga University \\ ${ }^{2}$ Dental Clinic, Faculty of Dentistry, Airlangga University \\ Surabaya - Indonesia
}

\begin{abstract}
There is a possible relationship between dental plaque and children allergic diseases. According to literatures, gingivitis suffered mostly by allergic children than control. Case reports also revealed that dental plaque control therapy was able to reduce, even eliminate rhinosinusitis and asthmatic symptoms without additional medications. However, the exact method for confirming the gingivitis-related allergy is still uncertain. Allergic diseases have multifactorial etiologies and dental plaque had been proposed as a new trigger of allergic symptoms. Nevertheless, since not every child with gingivitis suffered from allergy or vice versa, this uncertain phenomenon may lead to patients or other clinician disbelief. The objective of the present study was to propose a new method, which involving the Gingival immunologic defense index (GIDI) to evaluate the susceptibility to allergic diseases. GIDI is an index that had been developed earlier for evaluating gingival immunologic defense with respect to immunoglobulin A (IgA) levels. This index based on the simple count of the inflamed gingival surfaces of a child plus the measurement of salivary IgA content. It provides clinicians with important information about the immunologic defense potential of each subject. Interestingly, most allergic children also had inherited IgA deficiency, thus this concept is likely. Based on literatures, GIDI could be a potential index for evaluating the risk of allergic diseases through gingival health assessment. However, prior investigation to the value of Indonesian GIDI index which related to allergy should be conducted.
\end{abstract}

Key words: gingival immunity, index, allergy

Correspondence: Seno Pradopo, c/o: Departemen Ilmu Kedokteran Gigi Anak, Fakultas Kedokteran Gigi Universitas Airlangga. Jl. Mayjend. Prof. Dr. Moestopo no. 47 Surabaya 60132, Indonesia. E-mail: pradopo_seno@yahoo.com. Telp. (031) 5030255.

\section{INTRODUCTION}

The connection between periodontal and general health had been studied by abundant literatures. ${ }^{1,2}$ Nevertheless, the relationship with allergy is still in controversy. Evidence-base cases revealed that oral focal infection may cause urticaria, ${ }^{1}$ rhinitis,${ }^{3}$ and sinusitis symptoms; ${ }^{4,5}$ However, elimination of oral focal infection is not included in allergy management protocol. Thus, the involvement of gingival health status that also connected with systemic diseases which may include allergy is often overlooked. Unfortunately, it may lead to unnecessarily prolonged medications and treatments, including surgery (i.e. adenoidectomy for chronic sinusitis in children) in allergic children.

Dental plaque may also act as the source of oral focal infection, even inflammatory reaction in chronic gingivitis is able to elicit systemic pathology. ${ }^{2}$ Nevertheless, until now, the systemic pathology investigated was limited to adult diseases such as cerebrovascular and cardiovascular diseases, diabetes, pregnancy problems etc. ${ }^{1}$ The systemic effect happened to children was rarely studied. According to several investigators, allergic children, especially rhinitis and asthma had poorer periodontal health. However, these investigations revealed that allergic diseases caused poor oral health (caries and gingivitis) because of dry mouth or mouth breathing and not vice versa. ${ }^{6}$

Several literatures revealed the possible benefit of dental plaque control therapy to reduce allergic symptoms in children. ${ }^{3-5}$ Therefore, comprehensive treatment of allergy should also consider improving children's oral health, especially reducing dental plaque accumulation which account for gingivitis. Through gingivitis, dental plaque may lead to systemic pathology. ${ }^{2}$ Thus, optimal gingival health is considered beneficial to support allergic management, not only medications, immunotherapy or allergen avoidance dependent.

Regarding to this concept, the importance of gingival immunity which is also related to the occurrence of microorganism invasion, and the role of first line defense in gingival mucosa, the salivary immunoglobulin A $(\operatorname{sIg} A),{ }^{7}$ should be considered. In 1995, researches from Sao Paulo University, Brasil proposed the gingival immunologic defense index (GIDI) for evaluation of gingival immunologic defense with respect to salivary IgA levels. ${ }^{8}$ As the susceptibility of infection also related to allergic patient who also predisposed to lower secretory $\operatorname{IgA}$ (SIgA) levels. ${ }^{9}$ In addition, it is more pronounced in children who their IgA level still not full-developed until approximately the age of $10 .{ }^{10}$ 
The objective of this study is to introduce the GIDI as a practical indicator of gingival health for evaluating the risk of allergic diseases. Hopefully, this concept also encourages medical practitioners to evaluate gingival condition during examination of allergic patients.

\section{Basic immune system}

There are two important parts of immune system, the innate immunity and the acquired immunity. The simplest way to avoid infection is to prevent the microorganisms from gaining access to the body. The first line of defense which prevent from infection are skin, sweat, saliva, nasal secretions etc. Microbial and other foreign particles trapped within mucus secreted by the lining membranes are removed by mechanical action such as coughing and sneezing. ${ }^{9}$

For faster recognition and facilitate phagocytosis, antibodies were synthesized in part of the acquired immunity. There are several antibodies in the immune system that termed as immunoglobulins. The immunoglobulin $\mathrm{M}$ (IgM), $\operatorname{IgG}, \operatorname{Ig} \mathrm{A}, \operatorname{IgD}$ and $\operatorname{IgE}$ furthermore, there are two kinds of immunity mechanisms involved, the cell-mediated immunity and humoral immunity. Antibodies are mostly produced in humoral immunity which needs the interactions of T-cells and B-cells lymphocytes. ${ }^{10}$

\section{Immune system and allergic disease}

Allergic diseases are related to the subpopulation of T-cells so called the T-helper 2 (TH2) cells. These TH2 lymphocytes release cytokines upon stimulations that are interleukin 4 (IL-4) and IL-13 which able to induce antibody production by B-cells. Actually, in normal individuals, these cytokines stimulate immunoglobulin $\mathrm{M}(\operatorname{IgM})$ and IgG production which provide defence against bacteremia via opsonization. Nevertheless, in allergic individuals, these cytokines convert IgM and IgG to IgE through a mechanism so called "isotype switching". ${ }^{10}$ The increase of allergenspecific IgE in the circulation which then attached to the FceI receptors of immunocompetent cells such as mast cells and basophils make individuals more sensitive to allergens. ${ }^{1}$ In addition, IL-4 also inactivate macrophages which needed for phagocytosis of bacteria.

\section{Immunoglobulin A and allergic disease}

Immunoglobulin A ( $\operatorname{Ig} \mathrm{A})$ is the predominant immunoglobulin in seromucous secretions such as saliva, colostrums breast milk, tracheobronchial and genitourinary secretions. It is produced by mature B lymphocytes cells and related to the isotype switching mechanism which is regulated by transforming growth factor- $\beta$ (TGF- $\beta$ ). This cytokine is secreted by T-regulator (Treg) lymphocytes. (Male) Allergy is considered caused by inadequate Treg function (Romagnani).

Antigens, that are microorganisms and allergens before attaching to the mucosa are "blanket" by $\operatorname{IgA}$, which is the first immunoglobulin involved. ${ }^{11}$ Immunoglobulin A which also a constituent of saliva and termed as salivary $\operatorname{IgA}$ $(\operatorname{Ig} \mathrm{A})$ is a part of the secretory $\operatorname{Ig} \mathrm{A}(\mathrm{SIgA})$ of the human body. ${ }^{9}$ Failure of $\operatorname{Ig}$ A to protect antigens from adherence to the mucosa leads to further penetration of microorganisms and allergens into the mucosa and may lead to bacteremia. ${ }^{7}$ In children, IgA is the last immunoglobulin that reaches adult level. ${ }^{10}$

The connection between oral health, systemic diseases and allergy

There were abundant literatures related to systemic infection which originated from periodontal or pulpal infections through bacteremia or spread of pro-inflammatory mediators. Cerebrovascular, cardiovascular diseases were the most renowned; others are diabetes mellitus and pregnancy problems. ${ }^{1}$ Nevertheless, there were only several studies which related to allergy. Most literatures were epidemiological studies and concluded that allergic patients (i.e. rhinitis, asthma) had poorer oral health. ${ }^{6}$

Several case reports revealed that dental plaque control therapy had beneficial effect to children suffered from allergic rhinitis, sinusitis and asthma. ${ }^{3-5}$ Collaborated study which included dental practitioners, pediatrician and children allergic experts revealed that dental plaque therapy without medication lead to disappearing of clinical asthmatic symptoms; even after two months later. ${ }^{11}$

\section{Dental plaque and allergic diseases}

Bacterial dental plaque or dental biofilm consisted of microorganism and organic matrix. It contains Grampositive and Gram-negative bacteria which may cause bacteremia and trigger immunologic reaction by stimulating immunocompetent cells (i.e. mast cells, macrophages, basophils). Bacteria also able to activate the innate immunity, such as the complement system C3 which stimulate mast cell or basophil degranulation via $\mathrm{C} 3 \mathrm{a}$ receptor. ${ }^{12}$ Toxins from these bacteria, the peptidoglicans from Gram-positive bacteria and lipopolysaccharides from Gram-negative bacteria stimulate toll-like receptor-2 (TLR2) and TLR4 respectively. These TLRs are present in immunocompetent cells i.e. mast cells, basophils, macrophages. $^{13}$

\section{Gingival immunological defense index (GIDI)}

The gingival immunologic defense index (GIDI), which is based on the simple count of the inflamed gingival surfaces of a child plus the measurement of salivary IgA content, provides clinicians with important information about the immunologic defense potential of each subject. The formula of this new index would not be static like the gingival index and that would not take into consideration only the severity of gingival inflammation, but that could be used to evaluate the gingival immunologic defense with respect to salivary content of $\operatorname{IgA}$, the major immunoglobulin in the oral cavity, under different gingival conditions. $^{8}$

To determine the relationship between gingival inflammation and salivary immunoglobulin content we created a new index that we propose to call GIDI, an index that seems to be appropriate for the evaluation of the 
immunologic defense of the oral cavity in the presence of gingival inflammation.

This index is the ratio between salivary immunoglobulin level ( $\mu \mathrm{g} \operatorname{IgA} / 100 \mathrm{ml}$ saliva) and number of inflamed gingival surfaces present in an individual. Ultimately, this index reflects the mean level of immunoglobulin secreted per inflamed gingival surface and can be expressed by the following equation:

$$
\text { GIDI }=\frac{\text { Ig level }}{\text { NIGS }}
$$

Ig is the immunoglobulin measured $(\mu \mathrm{g})$ and NIGS is the number of inflamed gingival surfaces.

The advantage of evaluating gingival immunologic defense by the GIDI in relation to simply determining the degree of gingival inflammation by the GI is that the GIDI permits the establishment of a prognosis for the evolution of the inflammatory process, leading to a dynamic evaluation of the latter, in contrast to the GI, which is simply a static determination. ${ }^{8}$

\section{The "neurogenic switching" mechanism}

This mechanism was introduced by Meggs in $1993,{ }^{14}$ which hypothesized that local inflammation was able to propagate or to spread to distant location via mast cellnerve fibers interaction. For example, allergic dermatitis may account for rhinitis or vice versa. It was confirmed by researches, i.e. by van der Kleij. ${ }^{15}$ According to Lundy and Linden, ${ }^{16}$ this mechanism also occurred in the periodontal tissues, including gingiva.

\section{DISCUSSION}

Allergic hyperreactivity is defined as an exaggerated immuneresponse typically immunoglobulin $\mathrm{E}(\mathrm{IgE})$ but also non-IgE mediated toward harmless antigenic stimuli. ${ }^{17}$ A practical method for allergic or hypersensitivity test is the skin prick test (SPT). ${ }^{9}$ Nevertheless, the detection of agents or factors which contribute to the severity of allergy is not easily conducted. Since allergic reactions mostly manifests as nasal, skin and asthmatic symptoms, the importance of early detection of allergic symptoms via oral cavity is often overlooked. Oral mucosa which is a port of entry of antigens inside our body could act as potential indicator or oral tolerance. ${ }^{18}$ Furthermore, poor gingival health in children may account for bacteremia, circulating pro-inflammatory mediators (Lie) and the neurogenic switching mechanism may help the assessment of allergic risk in allergic children.

Allergic children have the propensity to develop lower IgA level in several reasons: a) mostly predisposed to $\operatorname{Ig} \mathrm{A}$ deficiency; $b$ ) have lower or inadequate transforming growth factor- $\beta$ (TGF- $\beta$ ), cytokines produced by Tregulators (Tregs) which needed for isotype switching of IgA produced by B lymphocytes. ${ }^{19,20}$ Thus it is possible that allergic children are prone to bacterial and other antigens invasion, since they have lower level of salivary IgA which actually "blanket" the bacteria and antigens. This condition may lead to gingivitis in children, which in accordance with Laurikainen ${ }^{6}$ study.

According to the lower immunity and susceptibility of infection in allergic children, this concept is logical. Nevertheless, epidemiological study in adult by Friedrich revealed that periodontitis had a protective risk against allergy and asthma, which consistent with the "hygiene hypothesis". ${ }^{21}$ It was also in concordance with the oral tolerance concept, that is an inhibition of specific immuneresponsiveness to subsequent parenteral injections of proteins to which an individual or animal has been previously exposed via the oral route. Oral tolerance needs Tregs system that produces TGF- $\beta$ and interleukin 10 (IL-10) for its development. ${ }^{22}$ However, a study by Mucida et al. showed that Tregs were not necessarily needed in oral tolerance. ${ }^{17}$

It is logical that inflamed tissue, including gingivitis presents more vasodilated and increased permeability blood vessels. Other is loosened of epithelial tight junction caused by pro-inflammatory mediators such as tumor necrosis factor $\alpha(\mathrm{TNF}-\alpha){ }^{23}$ Therefore, increased evidence of microorganisms and antigens invasion could be predicted. Thus, the importance of first barrier of infection such as the $\operatorname{IgA}$ is mandatory.

The gingival immunologic defense index (GIDI) is considered as an "easy to be learned" and "easy to be done" indicator for either dental or medical practitioners, because it is only related to number of inflamed gingival surfaces (NIGS), and without specific clinical descriptions. To determine the degree of local immunologic defense conferred on the gingiva by $\operatorname{IgA}$, one should not consider the salivary $\operatorname{Ig}$ A content alone as an absolute value, but rather the level of secreted IgA per inflamed gingival surface $(\mathrm{GIDI}=\mathrm{IgA} / \mathrm{NIGS}){ }^{8}$

The problem is the relative difficulty in salivary $\operatorname{IgA}$ assessment procedures, which actually needs laboratory test. Nevertheless, this stage could be omitted, since IgA level in children under 10 is lower than normal. Especially allergic children have a predisposition of lower IgA level. The most important thing is to conduct a research investigating the average value of GIDI in non-allergic and allergic children in Indonesia.

The value of GIDI in allergic screening test could be contradictory with the new concept of oral tolerance which is not Tregs dependent. ${ }^{17}$ However, gingivitis also related to increased amount of bacterial toxins. According to Jung et al. ${ }^{24}$ in the presence of LPS, allergic reaction becomes exaggerated because of its synergistic effect with antigens.

The intention of this study is to find a practical indicator for allergic screening test, therefore practical indicator such as the calculation of GIDI whish is a simple count of the number of inflamed gingival surfaces of a child, taken 
together with the measurement of salivary IgA, can provide important information to the clinician in terms of the potential for gingival immunologic defense of the allergic children. Early detection of dental plaque infection risk in allergic children could anticipate for unnecessary prolonged allergy medications, treatments, or even surgery.

For the concluding remarks in order to increase the collaboration of medical and dental practitioners for preventing the development of children's allergic diseases, it is suggested that collaborated researches and forums should be conducted. In addition, there should be more informations which targetting laymen through print or electronic media which explain the connection between the dental plaque and allergy.

\section{REFERENCES}

1. Li XJ, Kolltveit KM, Tronstad L, Olsen I. Systemic diseases caused by oral infection. Clin Microbiol Rev 2000; 13(4):547-58.

2. Scannapieco FA. Periodontal inflammation: from gingivitis to systemic disease. Compendium 2004; 25(7):S17-S25.

3. Utomo H, Setijanto D. Apakah terapi pengendalian plak gigi dapat menurunkan keparahan rinitis alergika pada anak. Majalah Kedokteran Gigi (Dent J) 2005; 38(2):96-102.

4. Utomo H. Sensitization of sphenopalatine ganglion by periodontal inflammation: a possible etiology for sinusitis and headache in children. Majalah Kedokteran Gigi (Dental Journal) 2006; 39(2):63-71.

5. Utomo H, Pradopo S. A practical dental approach in children's rhinosinusitis management. Indonesian Dent J 2006; 13(3):133-6.

6. Laurikainen K. Asthma and oral health: a clinical and epidemiological study. Academic dissertation. Tampere: Tampere University Press; 2002. p. 1-182.

7. Rabson A, Roitt IM, Delves PJ. Really essential medical immunology. $2^{\text {nd }}$ ed. Carlton: Blackwell Publishing; p. 8-10.

8. de Souza-Gugelmin MCM, Ito IY, Maia Campos G. Creation of the gingival immunologic defense index (GIDI) to evaluate the immunological potential of the gingiva and the possible risk for periodontal diseases. Braz Dent J 1995; 6(2):95-102.
9. Leung DYM. In: Behrman RE, Kliegman RM, Jenson HB eds. Nelson's textbook of pediatrics. $17^{\text {th }}$ ed. Philadelphia: Saunders; 2004. p. 743-77.

10. McDade TW. Life history theory and the immune system: steps toward a human ecological immunology. Yearbook of Physical Immunology 2003; 46:100-25.

11. Utomo H. Reducing asthmatic symptoms through improving oral health: from imaginary to reality. J Indonesian Assoc of Dentistry 2008; Special Edition for Kongres PDGI XXIII.

12. Ali H, Panettieri RA. Anaphylatoxin C3a receptor in asthma. Respir Res 2005; 6:19-24.

13. Netea MG, Van der Meer JWM, Sutmuller RP, Adema GJ, Kullberg BJ. From the Th1/Th2 aradigm towards a toll-like receptor/T-Helper bias. Antimicrob Ag Chemoth 2005; 49(10):3991-6.

14. Meggs WJ. Neurogenic inflammation and sensitivity to environmental chemicals. Environ Health Perspect 1993; 101:234-8.

15. Van der Kleij H. Mast cell-nerve interaction. Academic dissertation. Utrecht: Universiteit of Utrecht; 2002. p. 1-161.

16. Lundy W, Linden R. Neuropeptides and neurogenic mechanism in oral and periodontal inflammation. Crit Rev Oral Biol 2004; 15(2):82-98.

17. Mucida D, Kutchukhidze N, Erazo A, Russo M, Lafaille JJ, de Lafaille MAC Oral tolerance in the absence of naturally occurring Tregs. J Clin Invest 2005; 115:1923-33.

18. Incorvaia C, Frati F, Sensi L, Riario-Sforza1 GG, Marcucci F. Allergic inflammation and the oral mucosa. Recent Patents on Inflammation and Allergy Drug Discovery 2007; 1:35-8.

19. Roitt I, Brorstoff J, Male D. Immunology. $6^{\text {th }}$ ed. Edinburgh: Mosby; 2001. p. 144-5.

20. Romagnani $\mathrm{S}$. The increased prevalence of allergy and the hygiene hypothesis: missing immune deviation, reduce immune suppression, or both? J Allergy Clin Immunol 2004; 112:352-63.

21. Friedrich N, Volzke H, Schwahn C, Kramer A, Junger M, Schafer $\mathrm{T}$, et al. Inverse association between periodontitis and respiratory allergies. Clin Exp Allergy 2006; 36(4):495-502.

22. Dubois B, Chapat L, Goubier A, Papiernik M, Nicolas JF, Kaiserlian D. Innate $\mathrm{CD} 4{ }^{+} \mathrm{CD} 25^{+}$regulatory $\mathrm{T}$ cells are required for oral tolerance and inhibition of $\mathrm{CD}^{+} \mathrm{T}$ cells mediating skin inflammation. Blood 2003; 102(9):3295-301.

23. Go M, Kojima T, Takano K, Murata M, Ichimiya S, Tsubota $\mathrm{T}$, et al. Expression and function of tight junction in the crypt epithelium of human palatine tonsils. J Histochem Cytochem 2004; 52(12):1627-38.

24. Jung YW, Schoeb TR, Weaver CT, Chaplin DD. Antigen and lipopolysaccharide plays synergistic roles in the effector phase of airway inflammation in mice. Am J Pathol 2006; 168:1425-34. 